\title{
Desentralisasi pengolahan limbah padat rumah tangga menggunakan teknologi biodrying
}

\author{
B. Zaman ${ }^{1}$, W. Oktiawan ${ }^{1}$, M. Hadiwidodo ${ }^{1}$, E. Sutrisno ${ }^{1}$, Purwono ${ }^{1 *}$ \\ ${ }^{1}$ Departemen Teknik Lingkungan, Fakultas Teknik, Universitas Diponegoro, Semarang, Indonesia
}

\begin{abstract}
Abstrak.
Pengolahan limbah padat rumah tangga dengan cara dibakar maupun landfill saat ini sudah tidak optimal. Ketersediaan lahan tempat pemrosesan akhir (TPA) sudah kritis, mencari alternatif TPA baru pun akan sulit dan mahal terutama di kota besar. Teknologi biodrying merupakan pengelolaan limbah padat dengan sistem desentralisasi, dimana limbah padat akan mengalami biokonversi mekanikal-biologikal. Pada prakteknya, reaktor biodrying memproses limbah padat dengan kadar air tinggi yang sudah dicacah dan menghasilkan output limbah padat kering sebagai bahan bakar pengganti batubara. Panas yang dihasilkan dari proses dekomposisi aerobik senyawa organik dikombinasikan dengan udara berlebih berfungsi mengeringkan limbah padat. Hasil penelitian menunjukkan bahwa limbah padat rumah tangga yang terdiri dari limbah makanan, daun, kertas, dan plastik memiliki kadar air awal sebesar 66,24 \%. Penambahan debit aerasi 2 liter/menit menghasilkan kenaikan suhu maksimum $44^{\circ} \mathrm{C}$ pada jam ke-29 dan bertahan sampai jam ke-39. Kadar air turun menjadi 62,18 $\%$ setelah diaerasi selama 110 jam. pH lindi yang dihasilkan mengalami kenaikan dari 6,07 (asam) menjadi 8,27 (basa). Parameter emisi udara $\mathrm{NO}_{2}$ mengalami penurunan dari $0,187 \mu \mathrm{g} / \mathrm{Nm}^{3}$ menjadi $0,008 \mu \mathrm{g} / \mathrm{Nm}^{3}$. Nilai ini hampir mendekati kadar $\mathrm{NO}_{2}$ udara ambien sebesar 0,006 $\mu \mathrm{g} / \mathrm{Nm}^{3}$. Berdasarkan penelitian ini dapat disimpulkan bahwa proses biodrying selama 5 hari mampu menaikan $\mathrm{pH}$ menjadi basa dan emisi udara $\mathrm{NO}^{2}$ rendah. Kadar air limbah padat perlu diturunkan lagi sampai $<20$ $\%$ agar dapat dibakar dengan baik.
\end{abstract}

Kata kunci: biodrying, limbah padat, kadar air, N02, suhu

\begin{abstract}
.
The processing of household solid waste by burning or landfill is currently not optimal. The availability of land where the final processing (TPA) is critical, looking for a new TPA alternative will be difficult and expensive, especially in big cities. Biodrying technology is solid waste management with a decentralized system, in which the solid waste will undergo a mechanical-biological bioconversion. In practice, the reactor bio-drying processing solid waste with high moisture content that has been chopped and produces a dry solid waste output (bio dried) as a fuel substitute for coal. The heat generated from the process of aerobic decomposition of organic compounds function combined with excess air drying of solid waste. The results showed that household solid waste consisting of food, leaf, paper, and plastic waste had an initial moisture content of $66.24 \%$. The addition of 2 liters/minute aeration discharge resulted in a maximum temperature increase of $44{ }^{\circ} \mathrm{C}$ at 29 hours and lasted for 39 hours. Water content decreased to $62.18 \%$ after aerated for 110 hours. The resulting leachate $\mathrm{pH}$ increased from 6.07 (acid) to 8.27 (base). $\mathrm{NO}_{2}$ air emission parameters decreased from 0.187 to $0.008 \mu \mathrm{g} / \mathrm{Nm}^{3}$. This value is almost near the ambient air $\mathrm{NO}_{2}$ level of $0.006 \mu \mathrm{g} / \mathrm{Nm}^{3}$. Based on this research it can be concluded that bio-drying process for 5 days was able to raise $\mathrm{pH}$ to become base with low $\mathrm{NO}_{2}$ air emission. The solid waste water content needs to be lowered to $<20 \%$ in order to be burned properly.
\end{abstract}

Keywords: biodrying, solid waste, water content, $\mathrm{NO}_{2}$, temperature

\section{PENDAHULUAN}

Timbulan limbah padat di seluruh dunia dapat menimbulkan masalah bila tidak dikelola dengan baik. Metode pengolahan limbah padat (sampah) dengan cara dibakar maupun landfill saat ini sudah tidak optimal. Ketersediaan lahan Tempat Pemrosesan Akhir (TPA) sudah kritis, mencari alternatif TPA baru pun akan sulit dan mahal terutama di kota besar. Pengelolaan limbah padat dengan sistem desentralisasi terutama di daerah perumahan perkotaan mampu

\footnotetext{
${ }^{*}$ Korespondensi Penulis

Email : purwono.ga@gmail.com
} 
mereduksi limbah padat dengan baik. Intensitas dan aktivitas perkotaan menghasilkan banyak limbah padat biodegradable yang harus dikelola untuk menghindari dampak negatif pada lingkungan seperti bau dan polusi emisi, tanah, air, gas, dan lain-lain.

Prinsip utama bagi setiap negara terkait pengelolaan limbah padat adalah pencegahan. Prinsip kedua adalah daur ulang (recycle) dan produksi energi (energy production). Prinsip terakhir yaitu pembuangan limbah padat tanpa daur ulang dan menghasilkan energi. Teknologi yang menarik beberapa tahun terakhir ini adalah Mechanical Biological Treatment (MBT) dan Biological Mechanical Treatment (BMT). Kedua proses tersebut dikenal dengan istilah Biodrying (Biological drying) dimana limbah padat akan mengalami biokonversi mekanikal-biologikal (Muller 2009). Teknologi biodrying mendukung sustaianable environment terkait pengolahan limbah padat. Jumlah limbah padat yang akan masuk ke TPA secara substansial akan berkurang. Secara signifikan meningkatkan jumlah limbah padat yang didaur ulang dengan memisahkan bahan (kaca, inert, besi dan non logam besi) yang tidak benar-benar terpisah di rumah (Negoi 2009).

Saat ini, kebanyakan studi dari proses biodrying fokus pada teknologi aerobik, yang menurunkan kadar air menjadi uap sebagai akibat suhu tinggi dan ventilasi yang memadai. Adani et al. (2002) dan Sugni et al. (2005) menunjukkan bahwa pengaturan aerasi yang tepat (misalnya, debit dan arah aliran) dan suhu mampu menurunkan kadar air secara efisien $(66,7 \%$ dari kadar air awal). Namun, prinsip teknologi biodrying aerobik adalah untuk mendorong penguapan menggunakan energi yang dihasilkan akibat degradasi bahan organik. Ketika perbandingan kadar air terhadap bahan organik biodegradable terlalu tinggi, maka panas yang yang timbul tidak cukup untuk menguapkan air. Di sisi lain, limbah padat akan membusuk akibat kandungan air yang tinggi. Jumlah air akibat pembusukan (lindi) dibatasi oleh dinding sel atau membran yang hancur. Adanya aerasi meningkatkan disintegrasi parsial dan hidrolisis senyawa organik makromolekul seperti C-Organik, selulosa, hemiselulosa, lignin, nitrogen total (Nguyen et al. 2007). Pada proses biodrying, senyawa organik volatil (VOC) seperti senyawa berbau busuk (belerang), aromatik, chlorin, terpena dan keton akan terlepas ke udara. VOC ini menjadi salah satu masalah utama terhadap pencemaran udara (He et al. 2005). Penelitian ini melakukan proses biodrying untuk mengolah limbah padat yang difokuskan pada pola perubahan suhu limbah padat, kadar air, dan emisi $\mathrm{NO}_{2}$.

\section{METODOLOGI}

Peralatan yang digunakan pada penelitian ini yaitu menggunakan miniatur reaktor berbentuk siklik dengan volume 120 liter yang dilengkapi dengan 
rangkaian aerasi. Pada ujung aerator ditambahkan difuser untuk mengoptimalkan aerasi. Kecepatan alir udara diatur sebesar $2 \mathrm{~L} / \mathrm{min}$. Kadar air sampah sekitar $70 \%$. Di dalam reaktor diharapkan terjadi proses biodrying. Lokasi penelitian ini dilaksanakan di Laboratorium Lingkungan, Jurusan Teknik Lingkungan Fakultas, Universitas Diponegoro.

\subsection{Pemantauan penelitian}

Parameter suhu dipantau setiap 3 jam sekali dan pH lindi dipantau setiap hari. Pengukuran suhu menggunakan termometer digital yang dilengkapi layar LCD untuk mempermudah pengamatan melihat suhu proses biodrying. Spesifikasi rentang temperatur antara $-50^{\circ} \mathrm{C}$ hingga $110^{\circ} \mathrm{C}$. Probe sensor diletakkan di bagian atas, titik tengah dan bawah reaktor, dan nilai rata-rata dicatat. Lindi yang dihasilkan dari reaktor dikumpulkan dan diukur nilai pH-nya.

Selama penelitian biodrying, setiap hari, sekitar $100 \mathrm{~g}$ sampel dikumpulkan dari tiga kedalaman berbeda (bagian atas, tengah dan bawah) dan dicampur untuk analisis nilai pH sesuai SNI 06-6989.11-2004. Semua parameter dianalisis triplo (rangkap tiga). Standar deviasi ditetapkan $<10 \%$. Pengukuran udara $\left(\mathrm{NO}_{2}\right)$ menggunakan larutan Griess Saltzman sehingga membentuk suatu senyawa azo dye berwarna merah muda yang stabil setelah 15 menit. Konsentrasi larutan ditentukan secara spektrofotometri pada panjang gelombang $550 \mathrm{~nm}$ (SNI 19-7119.2-2005).

\section{HASIL DAN PEMBAHASAN}

\subsection{Komposisi limbah padat}

Komposisi limbah padat yang digunakan dalam penelitian ini ditunjukkan pada Tabel 1.

Tabel 1. Komposisi limbah padat dari komplek Perumahan Korpri Tembalang, Semarang (w/w).

\begin{tabular}{clcc}
\hline No & Jenis Sampah & Kadar air (\%) & Prosentase limbah padat (\%) \\
\hline 1 & Daun & 13,30 & 49,98 \\
2 & Sisa Makanan & 32,30 & 10,59 \\
3 & Kertas & 11,30 & 4,26 \\
4 & Plastik & 12,10 & 8,64 \\
\hline
\end{tabular}

Komposisi tersebut menggambarkan keanekaragaman aktifitas masyarakat di Perumahan Korpri Tembalang, Semarang. Berdasarkan Tabel 1 dapat diketahui bahwa prosentase daun $(49,98 \%)$ paling banyak dibandingkan jenis sampah lainnya. Limbah plastik memiliki prosentase paling sedikit yaitu $8,64 \%(w / w)$. Kadar air setelah limbah padat dicampur kemudian diatur dengan menambah air sampai kadar air campuran sebesar 69\%. Pengaturan kadar air 
bertujuan untuk mengevaluasi kinerja biodrying untuk mengolah limbah padat dengan kadar air tinggi.

\subsection{Temperatur limbah padat}

Temperatur limbah padat, temperatur udara ambien, dan kelembaban udara selama proses biodrying ditunjukkan pada Gambar 1. Temperatur limbah padat pada awal proses sebesar $27^{\circ} \mathrm{C}$. Suhu ini bertahan sampai jam ke12. Temperatur ini mengindikasikan bahwa proses dekomposisi bahan organik belum berjalan secara efektif. Temperatur mengalami kenaikan cukup drastis mencapai $36^{\circ} \mathrm{C}$ mulai jam ke-19. Kenaikan temperatur merupakan dampak dari proses dekomposisi senyawa organik sederhana seperti asam amino, glukosa, asam organik dll (Kutzner 2000).

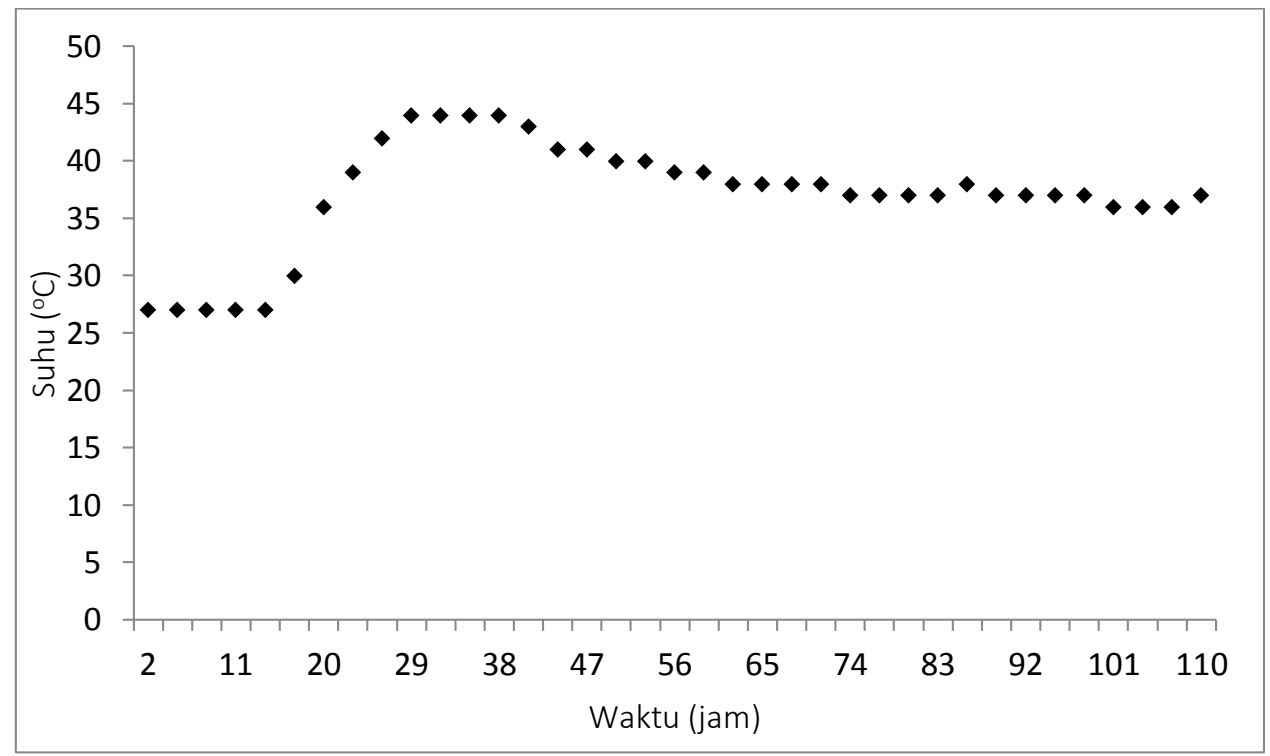

Gambar 1. Profil suhu limbah padat selama proses biodrying yang diamati per jam.

Senyawa tersebut dengan mudah dimetabolisme dan mineralisasi oleh bakteri heterotrof. Aktivitas metabolik dan proses eksotermik yang tinggi meningkatkan suhu limbah padat pada proses biodrying. Sebagai contoh reaksi katabolisme dalam sel bakteri.

Dekomposisi glukosa $\left(\mathrm{C}_{\mathrm{n}} \mathrm{H}_{2 \mathrm{n}} \mathrm{O}_{\mathrm{n}}\right)$ pada kondisi aerob melepas panas sebesar $896 \mathrm{~kJ}$ seperti reaksi berikut:

$\mathrm{C}_{6} \mathrm{H}_{12} \mathrm{O}_{6}+6 \mathrm{O}_{2} \longrightarrow 6 \mathrm{CO}_{2}+6 \mathrm{H}_{2} \mathrm{O} \Delta \mathrm{G}^{\mathrm{o}}=-2,872 \mathrm{~kJ}$ (panas)

Pola kenaikan berlanjut dan suhu ini merupakan puncaknya sebesar $44{ }^{\circ} \mathrm{C}$ yang bertahan pada jam ke-29 sampai jam ke-38. Suhu maksimal ini termasuk kategori mesofilik $\left(30-45^{\circ} \mathrm{C}\right)$. Jam ke-42 sampai jam ke-110 mengalami 
penurunan yang cenderung stabil pada kisaran suhu $39-36^{\circ} \mathrm{C}$. Menurut de Bertoldi (1983) penurunan suhu biodrying yang bertahap merupakan indikasi bahwa aktivitas mikoorganisme berjalan dengan baik. Apabila suhu turun drastis mengindikasikan proses gagal.

\subsection{Nilai pH limbah padat dan lindi}

Nilai pH 6,7-9,0 sangat mendukung aktivitas mikroba selama proses degradasi (de Bertoldi et al. 1983; Miller 1992). Data limbah padat dan lindi selama proses biodrying ditunjukkan pada Tabel 2.

Tabel 2. Nilai pH limbah padat dan lindi selama proses biodrying

\begin{tabular}{ccccc}
\hline No & Jam ke- & pH limbah padat & pH lindi & Kadar air (\%) \\
\hline 1 & 5 & 6,83 & 6,07 & 66,24 \\
2 & 29 & 7,02 & tidak terbentuk & 59,73 \\
3 & 53 & 7,36 & tidak terbentuk & 62,99 \\
4 & 77 & 7,28 & 8,27 & 62,27 \\
5 & 101 & 7,45 & 8,30 & 62,18 \\
\hline
\end{tabular}

Nilai pH limbah padat mengalami kenaikan dari 6,83 menjadi 7,45 pada jam ke-101 proses biodrying. Hal yang sama terjadi pada nilai $\mathrm{pH}$ lindi, $\mathrm{pH}$ awal sebesar 6,07 (asam) naik menjadi 8,30 (basa). Pada jam ke-29 sampai jam ke-35 tidak terbentuk lindi sama sekali. Artinya nilai $\mathrm{pH}$ masih berada pada range $\mathrm{pH}$ yang optimal untuk proses degradasi limbah padat. Menurut Mari (2005) nilai $\mathrm{pH}$ bukanlah faktor kunci keberhasilan proses dekomposisi. Nilai pH sangat relevan dengan emisi senyawa nitrogen (nitrogen-losses) volatil pada $\mathrm{pH}>7,5$. Pengontrolan $\mathrm{pH}$ harus dijaga agar tetap pada kondisi optimal. Pada $\mathrm{pH}$ tinggi dapat menyebabkan unsur nitrogen berubah menjadi amoniak yang mengakibatkan terjadinya bau. Pada $\mathrm{pH}$ yang terlalu rendah, dapat menyebabkan matinya sebagian besar mikroorganisme.

Kadar air awal diatur sebesar $66,24 \%$ denan cara menambahkan air kedalam campuran limbah padat. Kadar air mengalami penurunan menjadi 59,73 pada jam ke-25. Pada jam berikutnya cenderung stabil berkisar 62,99$62,18 \%$. Lama waktu biodrying 5 hari dengan debit 2 L/menit belum mampu menurunkan kadar air sampai $20 \%$.

\subsection{Kualitas udara $\left(\mathrm{NO}_{2}\right)$}

Emisi udara diukur untuk mengetahui dampak proses biodrying limbah padat terhadap kualitas udara. Pengukuran $\mathrm{NO}_{2}$ dilakukan pada saat suhu mencapai puncaknya $\left(44^{\circ} \mathrm{C}\right)$. Berdasarkan hasil penelitian menunjukkan emisi udara $\mathrm{NO}_{2}$ sebesar $0,187 \mu \mathrm{g} / \mathrm{Nm}^{3}$. Apabila dibandingkan dengan baku mutu $\mathrm{NO}_{2}$ di udara 
ambien menurut Surat Keputusan Gubernur Jawa Tengah Nomor 8 Tahun 2001, tentang Baku Mutu Udara Ambien di Provinsi Jawa Tengah sebesar $316 \mu \mathrm{g} / \mathrm{Nm}^{3}$. Hal menarik yang dihasilkan dari penelitian ini adalah penurunan emisi $\mathrm{NO}_{2}$ setelah suhu tertinggi tercapai. Pada rentang suhu $<41^{\circ} \mathrm{C}$ (suhu limbah padat), kadar $\mathrm{NO}_{2}$ mengalami penurunan menjadi $0,008 \mu \mathrm{g} / \mathrm{Nm}^{3}$. Nilai ini hampir mendekati kadar $\mathrm{NO}_{2}$ udara ambien sebesar $0,006 \mu \mathrm{g} / \mathrm{Nm}^{3}$.

\section{KESIMPULAN DAN SARAN}

Berdasarkan penelitian ini dapat disimpulkan bahwa proses biodrying selama 120 menit mampu mencapai suhu maksimal $44^{\circ} \mathrm{C}$. Nilai $\mathrm{pH}$ menjadi basa dan emisi udara $\mathrm{NO}_{2}$ rendah. Kadar air limbah padat perlu diturunkan lagi sampai $<20 \%$ agar dapat dibakar dengan baik.

\section{UCAPAN TERIMA KASIH}

Terima kasih kepada DRPM DIKTI atas pendanaan penelitian ini melalui hibah PUPT dengan kontrak pembiayaan tahun 007/SP2H/DRPM/V/ 2017 tahun 2017.

\section{Daftar Pustaka}

Adani F, Baido D, Calcaterra E and Genevini P L. 2002. The influence of biomass temperature on biostabilization-biodrying of municipal solid waste. Bioresource Technology 83(3):173-179.

de Bertoldi M, Vallini G and Pera A. 1983. The biology of composting: a review. Waste Managemenet Reserach 1:157-176.

He PJ, Shao LM, Qu X, Li GJ and Lee DJ. 2005. Effects of feed solutions on refuse hydrolysis and land fi ll leachate characteristics. Chemosphere 59(6):837844.

Kutzner HJ. 2000. Microbiology of Composting, in Biotechnology: Environmental Processes III, Volume 11c, Second Edition, Second Edition. Wiley-VCH Verlag GmbH. Weinheim. Germany.

Mari I. 2005. Use of sulfur to control pH in composts derived from olive processing by-products. Compost Sci. Util. 13:281-287.

Miller FC. 1992. Composting as a Process Based on the Control of Ecologically Selective Factors. In: Meting, F.B., Jr. (Ed), Soil Microbial Ecology, Applications in Agricultural and Environmental Management. Marcel Dekker, Inc. New York. p 515-544.

Sugni M, Calcaterra E and Adani F 2005. Biostabilization-biodrying of municipal solid waste by inverting air-flow. Bioresource Technology 96(12):13311337. 
Nguyen PHL, Kuruparan P and Visanathan C. 2007. Anaerobic digestion of municipal solid waste as a treatment prior to landfill. Bioresource Technology 98(2):380-387. 